\title{
Un cercano amigo de Francisco I. Madero
}

Beatriz Gutiérrez-Mueller

Investigadora

Benemérita Universidad de Puebla

México

\section{Resumen}

Este ensayo analiza la estadía de Rogelio Fernández Güell en México y las razones que lo llevaron al exilio en este país, donde entabla amistad personal con Francisco I. Madero.

Palabras clave: Rogelio Fernández Güell, Francisco I. Madero, exilio costarricense en México, Temas de Nuestra América, Cátedra del Exilio

\section{Abstract}

This research analyzes Rogelio Fernández Güell stay

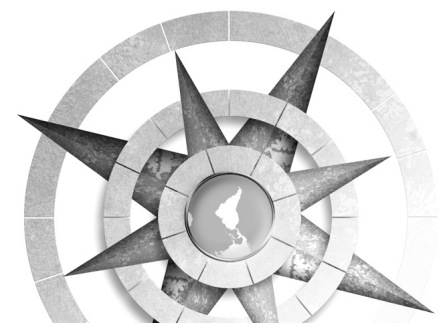

in Mexico and the reasons that forced that him to the exile in this country where he established personal friendship with Francisco I. Madero.

Keywords: Rogelio Fernández Güell, Francisco I. Madero, Costa Rican exile in México, Temas de Nuestra América, Exile Research Group

En el mes de mayo de $1905^{1}$ llegaba a la capital mexicana un joven flaco, de pómulos marcados y frente amplia, bigote ralo, pero bien acicalado, y fino cabello, peinado con gomina hacia

1 Según el Archivo Histórico Genero Estrada, de la Secretaría de Relaciones Exteriores (AHGE-SRE), que contiene una fotografía, Rogelio Fernández Güell habría llegado al país en esa fecha, la cual no se explicaría con la de su matrimonio con Rosa, supuestamente celebrado en Barcelona, el 15 de septiembre de 1906, según Eduardo Oconitrillo García, Rogelio Fernández Güell: escritor, poeta y caballero andante, San José, Editorial Costa Rica, 1981, p. 52. En el expediente de marras, se asienta que era propietario de una casita en Progreso No. 5, en Guadalupe Hidalgo, Distrito Federal, por los rumbos de la Villa de Guadalupe. AHGE-SRE, Departamento Consular, exp. I7131/1112 (1907-1911), f. 3. 
atrás, con una raya a la izquierda. Su nombre era Rogelio Fernández Güell. Al lado suyo venía su esposa, con quien se había casado en España. Ninguno de los dos era mexicano. Quizá, nunca antes habían estado en México. Él acababa de titularse como licenciado en Derecho y en Filosofía por la Real Universidad de Madrid y ya podía presumir de hablar inglés, portugués, catalán, provenzal, latín y griego. Ella se entendía en catalán y era, además, prima suya. Su nombre: Rosa Serratacó Soley. Tuvieron tres hijos: uno, nacido en Estados Unidos; otro, en México y, el último, en Costa Rica.

\section{Fotografía 1.}

\section{Rogelio Fernández-Güell}

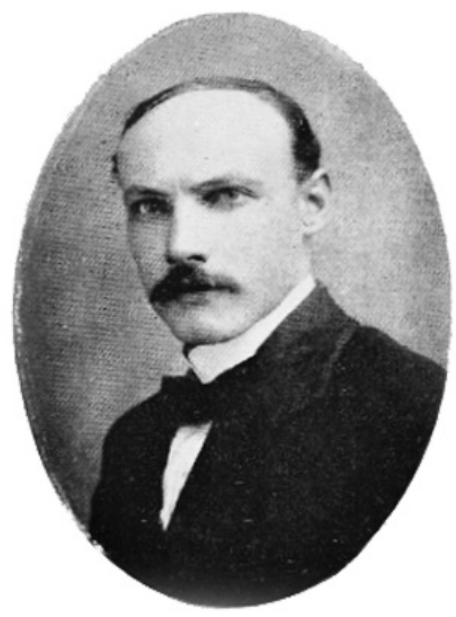

Fuente: Episodios de la revolución mexicana, San José, Imprenta Trejos Hermanos, 1915. Cortesía de la Biblioteca Nacional Miguel Obregón Lizano, San José, Costa Rica.
En los años por venir, la naciente inclinación intelectual de Fernández Güell habría de ampliarse hasta convertirse en un genuino homme de lettres, como se llamó a la generación de caballeros humanistas, intelectuales, políglotas, cultos y liberales de finales del XIX y principios del XX. En nuestro país -hasta que tuvo que huir, a la caída de Francisco I. Madero-escribió varios libros, artículos filosóficos y periodísticos y dictó conferencias; además, trabajó para tres administraciones (Porfirio Díaz, Francisco León de la Barra y Madero) y nada menos que dirigió, aunque por un breve lapso, la Biblioteca Nacional.

Rogelio había salido mucho antes de su país natal, Costa Rica. Aún sin tener mayoría de edad, militaba en el Partido Republicano, y había pisado la cárcel por escribir un artículo periodístico contra el gobierno, en El Tiempo. Diario Independiente, dirigido por Rafael Alpízar quien también llevó El Día. Diario Independiente, y donde colaboraba, asimismo, nuestro autor. Todavía en prisión (de veinte días), prosiguió con los señalamientos contra el gobierno de Rafael Yglesias Castro, en El Día, con una serie titulada "Elecciones". La tercera entrega fue firmada desde la «cárcel de San José», el 29 de julio de 1901. ${ }^{2}$ Sus pseudónimos, en San José, fueron:

2 Eduardo Oconitrillo García, op. cit., p. 25. 
Pascual y Sansón Carrasco muy joven y, al retornar, a partir de 1913 fueron; Ursus, Juvenal, Perseo y Viriato, según su principal biógrafo, Eduardo Oconitrillo.

¿A qué se oponía el joven periodista? Él era un demócrata convencido y Costa Rica estaba por realizar elecciones presidenciales. Se rumoraba que habría un 'arreglo' de Yglesias Castro con Ascensión Esquivel y Cleto González Víquez y esto, a todas luces, era inadmisible para él. Entonces, escribió (aunque no firmó): ${ }^{4}[$ [... entrar en pactos, imponer diplomáticamente a un candidato, buscar él mismo el hombre que le suceda como continuador de un sistema administrativo de funestas consecuencias para el país [...], eso no se conforma con la democracia ni con el decoro y buen juicio que deben asistir a un pueblo celoso de su dignidad y de sus fueros. ${ }^{5}$

3 Martha Celis de la Cruz, "Rogelio Juan Fernández Güell en México (1883-1918)”, en XII Jornadas Académicas 2010. Instituto de Investigaciones Bibliográficas, Biblioteca Nacional, Hemeroteca Nacional, Yael Coronel Navarro y Ma. Bertha V. Guillén [Eds.], México, UNAM, 2013, p. 167.

4 Iván Molina Jiménez, "Elecciones y democracia en Costa Rica, 1885-1913”, European Review of La tin American and Caribbean Studies, No. 70, 2001, pp. 44-45. Y ganaron los dos porque se rotaron: primero, Esquivel gobernó de 1902 a 1906 y le sucedió González Víquez, de 1906 a 1910.

5 "Nuestra actitud", en El Derecho, San José de Costa Rica, 22 de septiembre 1901, p. 2. Sistema Nacional de Bibliotecas de Costa Rica.
Tras los comicios de 1901, bajo el pseudónimo de Pascual, Rogelio aceptó la derrota de su partido aunque celebró un triunfo moral: "hicimos comprender al pueblo que tenía derechos que a nadie le era permitido restringir [...]; en fin, que era el verdadero soberano, el único dueño del Estado y que los gobernantes debían inclinarse ante su soberana voluntad". ${ }^{6}$ El Derecho había surgido para combatir al régimen.

De 1902 a 1903 siguió en el periodismo. En un incidente en el Parque Central de San José, por supuestamente hablar en contra del Ejército, recibió varios sablazos que lo hirieron en una mano y en un brazo. Se mudó al pequeño pueblo de Atenas, en la ciudad de Alajuela. Pero la hostilidad no mermó y, aunque esta vez sin heridas, se batió en duelo contra Luis Castro Ureña, en La Sabana, algún día de 1902. ${ }^{7}$ Publicó algunos poemas en Pandemónium: ¡Luz, luz, más luz! (1903), La calumnia (1903) y La leyenda de Boruca, (1903). Sin embargo, su relación con el gobierno no mejoró. Para enero de 1904, de forma subrepticia, decidió exiliarse en España. En El Centinela. Diario Republicano, de Carlos Orozco Castro, dejó escrito un «Adiós»:

6 Pascual, "Defendiendo la bandera”, en El Derecho. Diario Republicano y de Intereses Generales, San José de Costa Rica, No. 72, 29 de diciembre de 1901, p. 2. El periódico había nacido en 1901. Sistema Nacional de Bibliotecas de Costa Rica.

7 Eduardo Oconitrillo García, op. cit., p. 38 y 40. 
Nunca, como ahora, el sentimiento patrio ha causado en mí mayor fuerza [...]. Lamento dejar el suelo de la patria, no haber podido imprimir profundamente las huellas de mi paso en él [...]. Al escribir, siempre he tenido ante los ojos la imagen de la $\mathrm{Pa}$ tria. [...]. He combatido cuanto he juzgado dañoso para sus intereses y fatal para su honor [...]. Al colocar mi lanza en el armero, el corazón me dice que brazos más vigorosos la empuñarán en defensa de las ideas republicanas [...]. A los «eternos idealistas», a los «neos irreductibles», á esos no les digo adiós sino hasta luego. Y á los costarricenses todos [...] les puedo asegurar en este instante solemne de mi vida que, por Costa Rica, he luchado [...] y que, si yo salgo de la Patria, la Patria no saldrá nunca de mí. ${ }^{8}$

Llegó a Madrid, tenía 21 años, y de inmediato se relacionó con periodistas e intelectuales. ${ }^{9}$ Para 1905 , ya colaboraba para la revista Unión Ibero-Americana y fue, incluso, entrevistado sobre la

8 Rogelio Fernández Güell, “Adiós”, en El Centinela. Diario Republicano, San José, Año II, No. 209, pp. 2-3. Sistema Nacional de Bibliotecas de Costa Rica.

9 Oconitrillo García colocó a su primo, Tomás Soley Güell, como acompañante en este exilio. Los dos viajaron por la península varias veces. reciente independencia de Panamá. ${ }^{10}$ Esta revista contaba ya con las colaboraciones de José María Vargas Vila y José Santos Chocano, con quien se reencontraría en México. A mediados del año, la misma publicación homenajeaba a Miguel de Cervantes, y el costarricense

leía un poema en su honor. ${ }^{11}$

Viajó a Barcelona donde conoció a su futura esposa y retornó a Madrid para terminar sus estudios en la capital. Colaboraba, ahora, para otras publicaciones de la península. Hallé, en Páginas Ilustradas, el relato Cristo y Quijote y el poema María Magdalena [ambos, de 1905]; éste último saldría en el diario La Época, de México, del cual escribiré más adelante. De 1906, fue El mirador de América. Por su parte, en Acacia. Revista Masónica Internacional, con sede en Uruguay, salió la serie Mitos Bíblicos [1905], que la revista volvió a publicar en 1921.

10 "Presidentes actuales de las Repúblicas Ibero-americanas”, Unión Ibero-americana, Madrid, núm. 12, 1904, p. 17-18. Biblioteca Nacional de España.

11 "La Unión Ibero-Americana”, El Correo Español, Madrid, Año XVIII, No. 4,928, 16 de mayo de 1905, pp. 2-3. Biblioteca Nacional de España. Una corta lista de su nuevo círculo poético fueron los asistentes a dicha velada: los españoles Carlos Méndez Bejarano, Antonio Balbín de Unquera, José María Ortega Morejón y el padre Francisco Jiménez Campaña (poeta y miembro de la Real Academia Española de la Lengua), y los colombianos Santiago Pérez Triana y José María Vargas Vila. 
En Madrid, conoció a Rubén Darío, en la compañía de José Santos Chocano y Francisco Villaespesa. Darío conversaba con Jacinto Benavente mientras el joven exiliado los observaba:

Confieso que la impresión que me produjo el divino poeta fue muy distinta de la que yo esperaba. El hombre que tenía delante no era un bardo quejumbroso, melenudo y soñador como mi amigo Villaespesa [...], sino un buen burgués gordo, ancho de espaldas, algo barrigón, muy moreno, ancho de rostro y de sonrisa franca, vestido con cierta elegancia, si bien no con distinción, y con el chaleco cruzado por una gruesa cadena de oro, al estilo antiguo. ${ }^{12}$

Este tipo de descripciones las repetiría en Episodios, intentando capturar no solo los rasgos físicos del protagonista (Madero) y de los antagonistas (Victoriano Huerta, Aureliano Blanquet, Francisco León de la Barra, Félix Díaz y otros), sino el alma, el vaho que emanaba de su personalidad. Lo mismo trató de hacer con El moderno Juárez, que hizo en 1911, obrita que abordaré páginas más adelante.

12 Eduardo Oconitrillo García, op. cit., p. 49.
Después de un año y medio en España, tomó un vapor a México. Aunque esta segunda parte de su exilio pudo agradecerla por la relación que tenía con Ignacio Mariscal, entonces secretario de Relaciones Exteriores, en honor a la verdad, no hay documento que haya encontrado que garantice esta hipótesis. Hipótesis sólo fundamentada en la intensidad por el estudio, en él y en Mariscal, por la ciencia espírita. Por lo demás, en el apogeo del Porfiriato, México siempre fue un país atractivo para el desarrollo profesional, la vida cultural y artística y el estudio. También, fue cobijo para exiliados.

Su primer empleo fue en el Observatorio Astronómico Nacional de Tacubaya. A la par, se acercó a la Junta Central Permanente Espírita de México que iba a tener su primer congreso nacional del 31 de marzo al 15 de abril de 1906 (a distancia, conservaba su membresía en la Liga Espiritista Española). El costarricense participó con la ponencia "Espiritismo y teosofía". ${ }^{13}$ Sin duda, su profundidad en el tema lo convirtió, desde entonces, en uno de los máximos representantes, en el mundo hispano, de esa, considerada por entonces, como una ciencia. Francisco I. Madero -no

13 Rogelio Fernández Güell, "Espiritismo y teosofía", en Primer Congreso Nacional Espírita. Junta Central Permanente. Conferencias, México: A. García Cubas sucesores, 1907, p. 87. 
es novedad afirmarlo- era un ardiente apasionado de esa doctrina. A algún lugar fuera de México debió viajar, sin saber cuál, pues la ruta del tren lo llevó a pasar por Río Blanco, Veracruz, el 7 de enero de 1907. Ese día ocurría una de las más brutales represiones obreras en la fábrica de tejidos de la localidad: "Los negros muros de la fábricas presenciaron estos horrores de los que el autor conserva un doloroso recuerdo, pues pasó por estos lugares el mismo día de la tragedia”, escribió en Episodios de la revolución mexicana. ${ }^{14}$

En 1907, tomaba la decisión de continuar su exilio en Estados Unidos. Debió recibir una buena oferta de su protector Mariscal pues se naturalizó mexicano el 23 de mayo de 1907. El general Porfirio Díaz lo nombró cónsul de México en Baltimore unos meses después, el 5 de noviembre de $1907 .{ }^{15}$

14 Rogelio Fernández Güell, Episodios de la revolución mexicana, San José, Imprenta Trejo Hermanos, 1915.

15 AHGE-SRE, exp. 698, año 1906-1907, III 521.2 (728.3) f. [8]. Antes, se le había expedido un nombramiento para ir a Kansas City, el cual "se suspende por orden superior" (f. [1]). Su sueldo asignado fue de 4,015 dólares anuales. En el expediente, sobresale el exequatur de beneplácito de Theodore Roosevelt, quien firmó su respectiva carta. Para el 3 de diciembre de 1907, ya despachaba como cónsul. Oconitrillo García, basado en una carta de Rogelio a su primo Tomás Soley Güell, asegura que, por el contrario, rechazó renunciar a su nacionalidad costarricense porque una nueva ley para el servicio exterior le obligaba a naturalizarse mexicano: "Con gusto aceptaría la
Tampoco en Estados Unidos perdió su larga vinculación con Costa Rica ni con España donde comenzó a colaborar para El Diario Ilustrado, de Madrid, y Luz, Unión y Verdad, de Barcelona. Ambas eran publicaciones espíritas. ${ }^{16}$ Oconitrillo halló también algo en Los Albores de la Verdad, revista que dirigía, desde 1904, Jacinto Esteva Marata, otro promotor espírita. ${ }^{17}$

nacionalidad mexicana, porque pienso que un latino americano está en su propio país en cualquiera de las Repúblicas del Mundo de Colón y porque México es para mí tan querida como aquella en que ví la luz; pero no me avengo a renunciar de mi nacionalidad por conservar una posición. Si esa renuncia me fuera pedida porque así lo requiere la salud, el bienestar o la prosperidad de México, en el acto me hubiera sentido mejicano", Eduardo Oconitrillo García, op. cit., p. 55.

16 Un curioso episodio, de 1909, revela la amistad que tuvo Rogelio con Roberto Brenes Mesén, Secretario de Instrucción Pública en Costa Rica y miembro de la Academia Costarricense de la Lengua. Fernández enviaba unas fotografías del «Círculo Franklin» en las que se aprecia a Brenes Mesén observando la 'aparición' de un espíritu a una médium de nombre Ofelia y otros dos testigos. El remitente pedía al editor, Jacinto Esteva Marata, (el de Los Albores de la Verdad, también en Luz, Unión y Verdad) que las publicara: "En verdad, todo cuanto sucede en Costa Rica es maravilloso [...]. Yo no soy testigo presencial de los referidos hechos; pero salgo garante de la veracidad de las personas que han participado de ellos. Todas me son íntimamente conocidas": "Psicología trascendental", en Luz, Unión y Verdad, Barcelona, Año X, núm. 10, octubre de 1909 , p. 153 . Biblioteca Nacional de España.

17 Eduardo Oconitrillo García, op. cit., p. 51. Lamentablemente, no enlistó algunas de ellas. 
Instalado en Maryland, todo parece indicar, lo que le sobraba era el tiempo. Y debió haberlo empleado para viajar, pensar, leer y escribir pues, como él mismo cuenta, durante su gestión, al 7 de mayo de 1909, Rogelio reportaba al Ministerio de Relaciones Exteriores "[...] la única dificultad que se me ha presentado en el ejercicio del cargo para el que tuvo a bien designarme": dos días antes, al consulado se había presentado un agente de la compañía F. Shallus con el manifiesto y patente de su vapor Kyleakin. Requería su certificación pero no quería pagar los derechos. El problema se solucionó sin contratiempos, aunque dicho agente firmó bajo protesta.

En Baltimore, Rogelio escribió un poemario que iría a las prensas catalanas pero "contenía tantas erratas que no autoricé su publicación», y el manuscrito inédito quedó en posesión de su esposa. ${ }^{18}$ En esa ciudad había nacido su primer hijo, Juan Rogelio, en 1908.

Logró del Ministerio de Relaciones Exteriores viajar a España para atender su salud, a partir del 28 de mayo de 1909. Todavía, estando en Barcelona, pidió una prórroga y consiguió retornar a su consulado hasta el 11 de septiembre de ese año.

18 Rogelio Fernández Güell, "El testamento literario del poeta", en Athenea, San José, t. IV, núm. 2, 15 de marzo de 1920 , p. 862. Sistema Nacional de Bibliotecas de Costa Rica.
Por supuesto, el inicio de la revolución mexicana lo tomó por sorpresa en Estados Unidos. Y casi a la par de esta sublevación, luego de un poco más de tres años, su misión diplomática terminaba: en enero de 1911, cuando estaba en su apogeo la rebelión maderista, le informaban que prescindían de sus servicios diplomáticos. ${ }^{19}$ Así las cosas, Rogelio, Rosa y su hijo Juan Rogelio tomaron el tren de regreso a la capital, como él mismo asienta, poco antes de

19 Estos cambios no tuvieron que ver con la revolución sino con la muerte de Mariscal. El también escritor Federico Gamboa, nuevo ministro de Relaciones Exteriores, le mandaba decir, como a muchos otros funcionarios, que ya no había empleo para ellos (AHGE-SRE, exp. I7131/1112, f. 64 y ss). Recibió 410 dólares como compensación para viajar a México. La vida volvió a encontrar a Rogelio y a Gamboa: cuando el primero se puso al frente de la Biblioteca Nacional, al parecer, ordenó cambiar de lugar el archivo y biblioteca del segundo que, se deduce, allí residían, razón por la que estos casi se perdieron y pudieron ser salvados "milagrosamente", según sus detractores, véase en Alberto María Carreño, en Memorias de la Academia Mexicana. Edición facsímil, Tomo VII (1945), Ciudad de México, Academia Mexicana, 1975 , p. 144. Gamboa, es pertinente asentar, fue de los pocos escritores que dejó por escrito haber leído Episodios. En su diario, el día 13 de julio de 1915, anotó: "Entro en funciones, enfrascándonos en copiosas lecturas de libros que he de juzgar. Me leo los Episodios de la Revista [sic] Mexicana de Fernández Güell [...]”. Max Henríquez Ureña en su Historia del modernismo lo incluye como uno de los grandes modernistas costarricenses, que dejó un libro, hoy difícil de encontrar por haber sido destruida casi toda la edición: Los Andes y otros poemas En línea: [http:// studylib.es/doc/491046/intelectuales-centroamericanos-en-el-ateneo-de-la-juventu... Consultado el 19 de abril de 2017]. 
la batalla de Casas Grandes, verificada el 6 de marzo de 1911.

Rogelio veía con antipatía la revolución mexicana, encabezada por Madero: «me pareció un atentado contra nuestra doctrina y una claudicación imperdonable en uno de los paladines más distinguidos del pacifismo». Mas pronto recapacitó: "La tragedia de la casa de Serdán me reveló el abismo. El infierno abrió su boca y por esa negra abertura pude contemplar un mundo de miseria y desesperación". ${ }^{20}$ Desde la ciudad de México, buscó la manera de entrevistarse con el caudillo lo más pronto posible. Quiso alcanzarlo en Bustillos para "disuadirlo de su bélica actitud (presunción inaudita, que revela cuán poco conocía yo el carácter de la revolución mexicana)", ${ }^{21}$ sin ser posible. El jefe de la revolución se había trasladado ya a Ciudad Juárez.

Entonces, Rogelio buscó a Francisco León de la Barra, otrora embajador de México en Estados Unidos, "a quien había conocido y tratado en Washington". De él obtuvo un salvoconducto "para que yo pudiera atravesar con toda

20 Rogelio Fernández Güell, Episodios, p. 64. Como es sabido, el 18 de noviembre de 1910, en Puebla, inició la insurrección liderada por Aquiles Serdán. Él y su hermano Máximo, además de otros insurrectos, fueron asesinados en su casa (sito Calle de Santa Clara No. 4).

21 Rogelio Fernández Güell, Episodios, p. 64. libertad las filas federales". Fernández Güell agregó que llevaba una misión paralela: entregarle una carta "de la Sociedad a [la] que tanto el Sr. Madero como yo pertenecíamos [...], que contenía un saludo de los compañeros y amigos y un fraternal llamamiento a la paz [así que,] a últimos de abril del referido año me dirigí a Ciudad Juárez por la vía de Laredo, San Antonio y El Paso Texas". ${ }^{22}$ Por cierto, el cronista jamás reveló el nombre de la Sociedad, no otra que la Junta Central Espírita de México. ${ }^{23}$

22 Ibid.

23 El texto íntegro del "saludo" es el siguiente: "Por acuerdo de la Junta se convino en que esta nota se pusiera personalmente en manos de usted, comisionando al hermano D. Rogelio Fernández Güe11 para ello y autorizándole, además, para que en las negociaciones de paz estuviera presente, á fin de coadyuvar á ella de una manera confidencial y humanitaria. " [...] La Junta confía en que, dado el amor que usted siempre ha manifestado hacia la causa del progreso y de la felicidad mundiales, atenderá debidamente al hermano Fernández Güell. "[...] Anhelamos que cese la guerra que ensangrienta esta bella porción del universo; que en aras del Amor se depongan los rencores y que la Libertad surja esplendorosa, no soberbia y engreida [sic] sobre cadáveres y ruinas, con la veste virginal manchada de sangre y con los ojos iluminados por el fulgor de la victoria, sino dulce y tranquila, á los vítores de un pueblo unido y en medio de las bendiciones de todos.

¡Gloria á Dios en las alturas y paz en la tierra á los hombres de buena voluntad!".

Por la Junta, Antonio B. y Castro, secretario de la Junta Permanente del Segundo Congreso Espírita de México", Biblioteca Nacional de México, Archivo Madero, Ms. M/119 c.1, Biblioteca Nacional de México, UNAM.
84 Un cercano amigo de Francisco I. Madero Beatriz Gutiérrez-Mueller

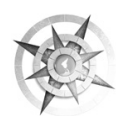


Al fin se conocieron Rogelio y Francisco I. Madero. Ambos sabían uno del otro, cuando menos, desde 1907. ${ }^{24}$

Llegó a El Paso, Texas el 26 de abril de 1911 y de ahí, se trasladó a pie al campamento del caudillo, en Ciudad Juárez. En una larga digresión autobiográfica, el autor de Episodios describió sus gratísimas impresiones de la familia Madero y, por supuesto, del líder. Se identificaron nada más verse. Tuvieron tiempo para apartarse de la casita de adobe que fungía como cuarto de guerra y charlar en privado: "En mi conversación con el señor Madero, nuevamente se reveló el hombre altruista, el filósofo de miras amplias y de sentimientos elevados de quien yo tenía noticia, y al volver a El Paso esa noche, mi corazón palpitaba de júbilo, pues veía cercano el fin de aquella lucha fratricida”. 25

A Fernández Güell le tocó vivir la intensidad de las más serias negociaciones del régimen de Díaz con los revolucionarios, y que terminarían con el fin de la revolución maderista. Todo ocurría en esa casita de adobe, en donde también se hallaban otros dirigentes que terminarían por ser pieza clave en la segunda fase de la revolución: Abraham González, José Vasconcelos, Venus-

24 Ver Francisco I. Madero, Epistolario. 1900-1909, ed. Agustín Yáñez y Catalina Sierra, Ciudad de México, SHCP, 1963.

25 Rogelio Fernández Güell, Episodios, p. 68. tiano Carranza y Pancho Villa, entre otros. De esos días en Juárez, el autor plasmó los recuerdos de ese futuro armisticio, y ofreció su propia paráfrasis de la tajante postura que manifestaba Carranza, futuro jefe de la revolución constitucionalista, quien declaró:

Nosotros, los verdaderos exponentes de la voluntad del pueblo mexicano [...] no podemos aceptar las renuncias de los señores Díaz y Corral, porque implícitamente reconoceríamos la legitimidad de su gobierno, falseando así la base del Plan de San Luis Potosí. La revolución es de principios, la revolución no es personalista [...]. Revolución que transa es revolución perdida. Las grandes reformas sociales sólo se llevan a cabo por medio de las victorias decisivas. [...]. Las revoluciones para triunfar de un modo definitivo necesitan ser implacables. [...] Lo repito: la revolución que transa se suicida. ${ }^{26}$

Rogelio no pudo quedarse a atestiguar la firma de los Tratados de Juárez, signados el 21 de mayo. Pero, conmovido, había escrito un soneto, firmado en la

26 Rogelio Fernández Güell, Episodios, p. 70-71. Recuérdese que, en julio de 1911, Díaz y Corral se habían reelecto en medio de un escándalo por fraude. 
fronteriza ciudad, con fecha 5 de mayo de 1911 y titulado A la paz:

¡Salud, gloria a la Paz; mas no a la diosa

que triste, avergonzada y abatida la dulce libertad llora perdida, manceba de calígulas odiosa! ¡Salud, gloria a la Paz, que surge hermosa

ante un pueblo viril de gozo henchida,

no arrastrando, Lucrecia envilecida,

por el fango la veste luminosa!

Surge, amable deidad, como una estrella

en el cielo brumoso mexicano, el llanto enjuga y los rencores sella. ¡Himnos, palmas, oh pueblo; canta ufano

que ante el mundo magnífica descuella

la Paz, con la Justicia de la mano!?

El 25 de mayo comenzaba el interinato de Francisco León de la Barra, su viejo conocido colega diplomático. Madero influyó, seguramente, para que Rogelio

27 El Amigo del Pueblo. Órgano del Club Libertador Francisco I. Madero, México, Año I, No. 1, 19 de julio de 1911, p. 4, LLILA-Benson Latin American Collection, University of Texas. Este poema, según la publicación, fue dedicado a Francisco I. Madero, Presidente Provisional de la República Mexicana, y fue escrito en el campamento del Ejército Libertador, el 5 de mayo de 1911. fuese nombrado jefe del departamento de Publicaciones del Museo Nacional de Arqueología, Historia y Etnología. ${ }^{28}$ A la par de su trabajo gubernamental, el costarricense se integró a las mesas de fundación del Partido Constitucional Progresista. ${ }^{29}$ Para contender en las elecciones extraordinarias de noviembre de 1911, era imprescindible reorganizar la vida partidista. Y contar con un periódico, por supuesto. Así, Rogelio quedó al frente del quincenal El Amigo del Pueblo. Órgano Oficial del Club Libertador "Francisco I. Madero", que promovía a Madero como Presidente. La vida de esta publicación, comenzada en julio, concluyó con la elección de octubre. Para ello, en ese mes, imprimió un tiraje de 80,000 ejemplares de El moderno Juárez. Estudio de la personalidad de Francisco I. Madero [México: Tip. Artística, 1911] que había

28 Inició en julio de 1911, Boletín del Museo Nacional de Arqueología, Historia y Etnología, Tomo I, agosto de 1911, p. 36. En el Boletín de noviembre de 1912 se anunció su salida para dirigir, ahora, la Biblioteca Nacional, noviembre de 1912, p. 109. Biblioteca Nacional de México, UNAM.

29 En torno a la discusión sobre la propuesta electoral que habrían de ofrecer, encontré un breve registro de una participación suya: "a este ciudadano se le concedió la palabra, pero tan solo en su exordio dio pruebas de la insuficiencia de sentido común al querer discutir en contra de las Leyes de Reforma, pues confundió lamentablemente la discusión de leyes con la de puntos religiosos. Una cosa es Bell y otra Güell”, El Demócrata Mexicano. Diario Libre, Ciudad de México, 21 de agosto de 1911, p. 1. Hemeroteca de la Secretaría de Hacienda y Crédito Público, México. Es lícito deducir que Rogelio defendía la libertad religiosa contra el monopolio de la Iglesia Católica. 
ido publicando en este diario proselitista. También, para entonces, pertenecía a la Federación y Confederación Espíritas Mexicana y Latino-Americana ${ }^{30}$ $y$, eventualmente, colaboraba en el periódico Nueva Era, donde proseguía la defensa de la revolución triunfadora, reproduciendo algunos artículos de $\mathrm{El}$ moderno Juárez:

El pueblo ha conquistado ya su libertad; ni tiranos lo oprimen, ni falsarios lo afrentan [...]. El señor Madero ha reconquistado la libertad para que gocen de ella todos los mexicanos; mas este inmenso beneficio no lo han comprendido los parias del porfirismo, los ilotas del antiguo régimen [...]. Se obstinan en permanecer en las tinieblas, la luz les hace daño [...]; les hace falta el peso de la cadena, lloran por la pitanza que les arrojaba con desprecio el carcelero. ${ }^{31}$

30 Rogelio dirigía, a su vez, la revista El Siglo Espirita, luego llamada Helios, la cual era el órgano informativo de la Junta Permanente del II Congreso Espírita de México, cuando menos, octubre de 1911. Oconitrillo García, por su parte, afirma que fue a partir de agosto de 1912, p. 61.

31 Rogelio Fernández Güell, "Los irredentos", en Nueva Era. Diario Independiente, Político y de Información, Ciudad de México, Año I, No. 151, 29 de diciembre de 1911, p. 1. Hemeroteca del Archivo General de la Nación, México.
Ese inolvidable año, lograba llevar a la imprenta Lux et umbra. Novela filosófica, [México, Tip. Artística, 1911] que tenía escrito desde México y que, seguramente, pulió en Baltimore. ${ }^{32}$ Es una historia defensora del credo espírita en donde hay varias ideas que retomará y repetirá en futuros trabajos. Por ejemplo, esta sobre el libre albedrío: "Sabed, hombres, que nosotros somos reyes, emperadores y pontífices de nosotros mismos" cuando se trató de defender la libertad del hombre; o aquella otra sentencia sobre que: "la mejor filosofía es aquella que nos enseña a amar la vida y nos procura relativa felicidad de que nos es dable disfrutar aquí en la tierra".33

Unos días antes de la toma de posesión de Madero, que fue el 6 de noviembre, Rogelio había tenido a su segundo hijo, al que puso por nombre Federico, como su padre y su hermano. El testigo fue su amigo, el también maderista y exiliado nicaragüense, Solón Argüello. Su casa estaba en la 2a calle de Farías.

Como Fernández Güell relata, ese día fue uno muy feliz para los "enamorados de la democracia”. Pero también fue el día en que los opositores decidieron no

32 La edición aparece fechada en México, 26 de marzo de 1907.

33 Rogelio Fernández Güell, Lux et umbra. Novela filosófica, ciudad de México, Tip. Artística, 1911, pp. 28 y 62 . 
descansar ni un día en idear la manera de derrocarlo. Así, en su crónica monumental registró uno a uno estos ardides y conspiraciones: desde la entrega de Bernardo Reyes en un cuartel de Nuevo León, su posterior fuga e inmediato ataque a Palacio Nacional (donde fue ultimado, el 9 de febrero de 1913), hasta las rebeldías de Pascual Orozco, Emilio Vázquez Gómez, José de Jesús Campos y Emiliano Zapata, pasando, entre otros, por el alzamiento de Félix Díaz, sobrino del desterrado general. Por supuesto, toda la trama que envolvió a los generales involucrados en el golpe de Estado: a la cabeza, Victoriano Huerta.

El año de 1912 fue más activo aún: política, poesía, filosofía y periodismo de tiempo completo. No encontré ninguna prueba que llevara a Rogelio hacia el primer círculo de la intelectualidad mexicana, agrupada en El Ateneo de la Juventud, sea como socio o como invitado o en la Academia Mexicana de las Letras. Sin embargo, mantuvo relación con varios conocidos miembros de éstas. En primer lugar, con los maderistas Jesús Urueta y José Vasconcelos y Luis Cabrera. El primero, ya era famoso no solo como orador (lo cual demostraría, según Episodios, en sus arengas parlamentarias como el «más brillante de los oradores mexicanos») en la XXVI Legislatura, sino como poeta y ensayista de arte, quien, además, daba conferencias literarias y escribía artículos periodísticos. El segundo iba a descollar, muchos años después, con reconocidas obras tales como Ulises criollo o La raza cósmica. No encontré tampoco mayores complicidades literarias o políticas de Rogelio con otros dos leales maderistas, como fueron el dramaturgo Marcelino Dávalos o Alfonso Cravioto. La explicación de su poca vinculación con los más altos círculos intelectuales, agrupados en sociedades literarias y el propio Ateneo o la Academia, estaría explicada de forma tácita en Episodios. Allí, el costarricense manifestó, en más de una ocasión, que la prosapia intelectual mexicana estaba demasiado vinculada con el Porfiriato. Aquí un caso, cuando escrutaba la situación dominante bajo la administración del general Díaz y que derivó en la primera revolución social del siglo XX:

México [...] era un imperio como Rusia o Turquía; los gobernantes eran maniquíes galoneados que el déspota ponía y quitaba a su capricho; los Estados eran satrapías [...]; la prensa doctrinarista y de combate, no existía; en las puertas de las redacciones había candados de oro cuyas llaves estaban en Chapultepec; los periodistas alquilaban sus plumas como los antiguos condottieri 
sus espadas; las oficinas de los diarios, pagadas por la Nación, no eran más que prolongaciones del Ministerio de Hacienda; el espíritu público estaba muerto y nadie se atrevía a pronunciar una sola palabra contra aquel orden de cosas. ${ }^{34}$

Con un integrante de la Academia, cuando menos, tuvo una polémica. Según un expediente de la Biblioteca Nacional de México, fue acusado de usar indebidamente un salón de la misma para recinto propio, donde tendría su biblioteca personal. El quejoso era, nada menos, Joaquín Diego Casasús, famoso abogado y amante de las letras y la cultura, mecenas de culto para poetas y pintores en aquellos años. Lo acusaba de no haber cedido dicho espacio, ya otorgado para la Academia desde el 11 de julio de 1911, por parte del gobierno de De la Barra. El escrito, firmado por Casasús, era enviado al Ministerio de Instrucción Pública, Justo Sierra, para que tomara cartas en el asunto. ${ }^{35}$ A propósito: sin tener ningún dato comprobable, la relación entre Sierra y Fernández Güell habría sido, sin duda, políticamente correcta. Sierra renunció a la par que Corral y Díaz; sin embargo, Madero lo nombró, primero,

34 Rogelio Fernández Güell, Episodios, p. 160.

35 Documento de fecha 7 de enero de 1913, ABN Carpeta 65, exp. 1322-3. Biblioteca Nacional de México, UNAM. ministro en dicha cartera y luego, embajador en España adonde murió en septiembre de 1912.

En las altas esferas políticas, era pública su enemistad con los articulistas de El Debate, como José María Lozano, o con el abogado y poeta Francisco Modesto de Olaguíbel quien dirigía El Mañana, junto con Jesús Rábago. ${ }^{36} \mathrm{O}$ con los de El Heraldo Mexicano. Y no se diga de El Imparcial, el más importante de su tiempo en el país. Allí eran predilectas las plumas de los escritores Luis G. Urbina y Carlos Díaz Dufoó. Ni hablar de las diatribas con Nemesio García Naranjo, director de La Tribuna, y quien llegó a estar como opositor principalísimo a Madero, en la XXVI Legislatura; o con Francisco Bulnes y La Prensa. Reflexionaba Fernández Güell: "Los periodistas en México formaban una especie de hermandad o "maffia", y su actitud obedecía indudablemente a un plan calculado, que tendía a desprestigiar al Gobierno y agravar la situación, para hacer posible un cambio". ${ }^{37}$

36 En La Época, Rogelio y Solón Argüello, incluso, crearon una sección poético-politica para burlarse de $E l$ Mañana, firmada por "Rabaguíbel", una trasposición de Rábago y Olaguíbel. Lozano, Olaguíbel, García Naranjo y Querido Moheno formaron parte del entonces llamado "Cuadrilátero", en la XXVI Legislatura. Su oposición a Madero y a la democratización del Poder Legislativo fue evidente.

37 Rogelio Fernández Güell, Episodios, p. 165. En la crónica reiteró, una vez más, su desprecio a los periodistas mexicanos: "Vicente Garrido Alfaro, 
Por ejemplo, el enfrentamiento periodístico con Emilio Vázquez Gómez, otrora impulsor del maderismo, no era simulado. En un artículo firmado como Zascandil, Fernández Güell se preguntaba de dónde venía el financiamiento para su rebelión, ahora, en contra de quien antes había apoyado en la lucha por el 'sufragio efectivo, no reelección'. Quería derrocar a Madero y convertirse él en Presidente "con incomprensible soberbia” y, ahora:

[...] pretende suplantar, valiéndose de la traición, la voluntad del pueblo mexicano, que espontáneamente eligió a Madero y que está de él satisfecho. [...] ¿Lo apoyan capitalistas yankees que han arrojado algunos miles de dólares en el tapete verde de nuestras convulsiones políticas, o bien se reservó alguna buena parte de los cinco millones que puso la Revolución en sus manos para el licenciamiento? ${ }^{78}$

Nemesio García Naranjo, Jesús Rábago publicaban en sus diarios noticias alarmantes y sensacionales, además de falsas mientras que otros inmundos pasquines, hacían blanco de sus ataques al licenciado Pino Suárez y al Ministro Bonilla, que representaban al elemento maderista en el Gabinete. El Diario y La Prensa eran neutrales; mas en sus columnas de vez en cuando exhalaba su aliento envenenado la "maffia" reporteri", p. 166.

38 Zascandil, "Historia de un crimen. Emilio Vázquez Gómez ante el tribunal de la conciencia pública, Parte II", en La época, bisemanario político, de información y variedades, Ciudad de México, Año I,
Otro caso coyuntural: Como Cimón, Rogelio arremetió en contra de los periodistas enemigos de Madero y de su familia, quienes los acusaban de estar «entrando á saco con el tesoro de la nación». A todas luces, esto era falso pues el Presidente no tenía necesidad por lo elevado de sus valores. Hacía memoria que el caudillo había puesto su cuantioso capital para financiar el alzamiento, lo que lo tenía, ahora, «materialmente arruinado» pero henchido de dignidad. Y juzgaba: en aquellos duros meses, los pseudo demócratas que se ufanaban de apoyar, no cooperaron con un peso ni con las tareas que se les pidió que realizaran. Daba unos ejemplos: el doctor Francisco Vázquez Gómez "se negaba en Washington a aceptar la Agencia Confidencial, por temor a comprometerse"; su hermano, Emilio, "entretenía sus ocios en San Antonio escribiendo anónimos al Sr. Madero contra los principales revolucionarios"; Francisco León de la Barra, "como Embajador del Tirano, perseguía en los Tribunales de Washington a Juan Sánchez Azcona, por conspirador”; y Alberto García Granados vivía con placidez en la ciudad de México, "mirando los toros desde la barrera". Respecto de los familiares del caudillo, involucrados en el movimiento armado, defendía:

Estos hombres nobles, estos

No. 3, 29 de febrero de 1912, p. 1. LLILA-Benson Latin American Collection, University of Texas. 
hombres puros, ¿habrán de ser vejados siempre sin que ninguna voz se levante y los defienda por el temor de que esa defensa se juzgue adulación, ya que es difícil que los malvados crean que se puede por un principio de virtud sin mezcla de vil interés sostener los fueros de la verdad? ¿Quién hay que pueda arrojar ni la sombra de una sospecha sobre la vida privada de esta familia, que representa todas las virtudes del hogar mexicano y la pureza romana de nuestros antecesores? Todos los señores Madero son hombres de carácter, honrados, emprendedores [...]. Mas el patriotismo les ha exigido este sacrificio que sabrá recompensarles algún día con un recuerdo cariñoso la Nación agradecida.

Como es sabido, llegó a México a mediados de 1912, para militar en el maderismo el peruano José Santos Chocano, a quien Rogelio había conocido en España. El poeta colaboró muchas veces para La Época. A ambos, también los unía la devoción por el espiritismo. Ya estaba en Monterrey Miguel Ángel Osorio Benítez, quien usó los alias de «Porfirio Barba Jacob» y «Ricardo Arenales», por los que, antes bien, fue conocido. Osorio se sumó a este pequeño grupo de intelec- tuales y artistas pro-maderistas.

Otras plumas con las que Rogelio colaboró y cultivó alguna amistad político-literaria fueron: el oaxaqueño periodista, escritor y abogado Manuel Brioso y Candiani; el filósofo Horacio Barreda, E. Echeverría, Hermilo Moreno y José Zorrilla; y los españoles Antonio Palomero, Pedro Muñoz Seca, Salvador Rueda y Juan Pérez Zúñiga, así como el veterano escritor, el colombiano José María Vargas Vila a quien, de toda seguridad conoció en Madrid pues ambos escribían para la revista Unión Ibero-Americana. Todos ellos le colaboraron en La Época. ${ }^{39}$

La revisión de periódicos de la época permite saber que mantuvo una buena relación de colegas con Juan Sánchez Azcona, Filomeno Mata y Félix F. Pa-

39 Zorrilla es el único que ya había fallecido. Estas colaboraciones aparecieron en la sección literaria del bisemanario; aún, la de Barrera. Brioso y Candiani se inspiraba en la sección editorial empleando el alias "Fray Verídico", según el ya citado Diccionario de Iguíniz. Cómo sería la tensión entre las dos principales facciones políticas de entonces, que Santos Chocano retó a duelo al diputado Nemesio García Naranjo. Véase: El país. Diario católico, 17 de noviembre de 1912, p. 1. Hemeroteca Nacional de México, UNAM. Es lugar aquí para recordar que Santos Chocano se fugó a Cuba, también a finales de 1913, desde donde pronunció un bravío discurso sobre los hechos que le había tocado presenciar en la Decena Trágica, responsabilizando a Victoriano Huerta como asesino y usurpador. Volvió a México. El gobierno lo acusó de ser un 'extranjero pernicioso'. 
lavicini, además de los periodistas y oradores Roque Estrada y Enrique Bordes Mangel. Es obvio que, conforme se agudizaron las posturas políticas de todos los involucrados, sobre todo hacia finales de 1912 y hasta la Decena Trágica, más bien se distanció de reputados poetas como Salvador Díaz Mirón o José Juan Tablada, ambos férvidos anti-maderistas. Incluso, su relevo en la Biblioteca Nacional fue Luis G. Urbina, quien se aceptó dicha cartera tras el golpe de Victoriano Huerta. ${ }^{40}$

Los blancos continuos en La Época, el cual dirigía dirigía, fueron, por supuesto, Alberto García Granados y Jorge Vera Estañol. No hallé vínculos asiduos con Alfonso Reyes, si acaso, el intento de sacar una publicación que pintaba como la gran revista del maderismo: Solón Argüello, Santos Chocano y Fernández Güell quisieron fundar México. Revista Mensual de Arte, Ciencia, Política y Variedades. Pero solo quedó en proyecto, el cual se conserva en el Archivo General de la Nación.

Francisco I. Madero la iba a apoyar.

40 Boletín de la Biblioteca Nacional de México, Año X, Nos. 1 y 2, marzo-abril de 1913, p. 2. Biblioteca Nacional de México, UNAM. Para mediados de año era subdirector Eugenio Zubieta y secretario Martín Luis Guzmán (Nos. 3, 4 y 5, mayo-junio-julio de 1913, p. 2). Francisco Sosa había sido su predecesor, y del mismo modo, no hallé ningún tipo de relación. La titularidad de la Secretaría de Instrucción Pública, con Huerta, recaía en otro oponente: Nemesio García Naranjo.
El boceto presentado al Presidente enlistaba a los futuros colaboradores: los nicaragüenses Rubén Darío y Santiago Argüello y el argentino Leopoldo Lugones; y, entre los mexicanos, Cravioto, Luis Castillo Ledón, Dávalos, Alberto Herrera, Luis Rosado Vega, Amado Nervo, Guillermo Eduardo Symonds, el pintor Jorge Enciso y el filósofo Antonio Caso, entre otros. ${ }^{41} \mathrm{Y}$, cosa curiosa: habría de escribir, también, una buena parte de los antimaderistas: Díaz Mirón, Urbina, Alfonso Reyes y Enrique González Martínez.

El agitado 1912 le permitió, sin embargo, llevar a la imprenta Psiquis sin velo. Tratado de filosofía esotérica (México: Müller Hermanos, 1912), dedicado a Francisco I. Madero. El manuscrito lo había firmado en Baltimore, en marzo de 1910. En éste siguió disertando sobre el espiritismo. Además, junto con Solón Argüello, fundó La Época. Bisemanario Político, de Información y Variedades, impreso en los talleres de la revista Helios. El primer número salió el 22 de febrero y habría terminado de editarse el último día de junio de 1912. En éste, Fernández Güell empleó los pseudónimos de Cimón, Zascandil, Francisco Dávalos y

41 Archivo General de la Nación (AGN), Fondo Presidentes, Francisco I. Madero, 1912, caja 76-A, exp. 5 , f. 1 y ss. 
Perdigones, ${ }^{42}$ y es muy probable que suyo también haya sido Madjahama. Con estos nombres se empleó, a fondo, en el ejercicio del periodismo militante. Un botón de muestra: para acusar, otra vez, a la prensa vendida, que se rehusaba a ser independiente y exigía dinero de las arcas públicas, contó la anécdota narrada por Michelet, cuando los parisienses se apoderaron de La Bastilla. Uno de los prisioneros liberados «pedía a grandes gritos que lo volvieran a su mazmorra»:

El desgraciado, que había envejecido en una de las torres de la tétrica prisión, no podía comprender el bien inmenso que la plebe acababa de devolverle; la luz le hacía daño; el ruido de las calles le ensordecía; el movimiento de la gran ciudad le aterraba. ¿Qué iba a ser de él fuera de la Bastilla? Temía morirse de hambre. ¡Ser libre! ¡Qué compromiso para el infeliz que no bien había andado una docena de pasos fuera del lúgubre castillo, cuando ya pedía llorando que lo volvieran á su calabozo, que no lo atormentasen más con el espectáculo de una libertad que él no había solicitado y que para nada necesitaba! ${ }^{13}$

42 Juan Bautista Iguíniz, Seudónimos, anagramas e iniciales de escritores mexicanos, México-París, Librería de la Vda. de Ch. Bouret, 1913.

43 Cimón, "La nostalgia del grillete", en La época, bisemanario político, de información y variedades, Ciudad de México, Año I, No. 1, p. 2. LLILA-Benson
Tal recreación servía para explicar la actualidad, al arribo del régimen maderista. Así sucede, concluía, "con muchas personas que lamentan la caída de la Dictadura, y que, como los licenciados o prófugos de presidio, arrastran el pie izquierdo, como si aún sintiesen el peso de la cadena, la horrible mordedura del grillete". ${ }^{44}$ Con otro artículo, el periodista volvió a la carga:

Dice el refrán que de la calumnia algo queda; mas si no se trata de combatirla y aplastarla, es indudable que queda todo. El pueblo es como el noble, magnánimo y valeroso Otelo: crédulo como un niño y fácilmente sugestionable [...]. La calumnia no respeta a los grandes hombres. Precisamente sobre las cumbres más altas y las torres más atrevidas descarga sus furias la tempestad [...]. La prensa enemiga se ha encargado de sugestionar al pueblo, a fin de

Latin American Collection, University of Texas, Fernández Güell luchó siempre por la libertad de expresión, según sus artículos periodísticos y sus obras. En otra de tantas disertaciones sobre el tema, se lee: "La larga dictadura del general Díaz engendró una prensa mercantilista y servil que aplaudía todos los actos del Gobierno y mantenía encendidos siempre los incensarios de su torpe adulación, como las sacerdotisas de Vesta el fuego sacro" (Episodios, p. 164).

44 Cimón, "La nostalgia del grillete", en La época, bisemanario político, de información y variedades, $\mathrm{Ciu}$ dad de México, Año I, No. 1, p. 2. LLILA-Benson Latin American Collection, University of Texas. 
que vea en el ilustre demócrata que nos gobierna [Madero] no al héroe de una revolución libertadora, sino a un ambicioso vulgar, a un tiranuelo de la talla del pequeño Napoleón. ${ }^{45}$

Mientras circuló La Época, aprovechó el espacio para publicar sus poemas. Algunos títulos que logré obtener, pues la colección conservada en la Universidad de Texas está incompleta, son: En América, A la paz (aquel de 1911 y publicado ya en El Amigo del Pueblo), El brindis de Petronio, En la sierra, A la conservación de la paz en América, de nuevo María Magdalena (de 1905), La amenaza del cí clope (del poema inédito «Los Andes») y Canción de amor (en la playa). ${ }^{46}$ De ellos tomó para el ejemplar perdido de Los andes y otros poemas, edición a la que faltó el último pliego: "el nuevo Ministro de Instrucción Pública (de Huerta) ordenó que fuese destruida la edición. Y lo fue". 47

45 Zascandil, "La sugestión de la prensa", en La época, bisemanario politico, de información y variedades, Ciudad de México, Año I, No. 226 febrero, p. 4. LLILA-Benson Latin American Collection, University of Texas.

46 En el inédito de Baltimore que el propio autor refirió en "El testamento literario del poeta", hay uno titulado Canción de amor. Quedaré a deber si se trata del mismo.

47 Rogelio Fernández Güell, "El testamento literario del poeta", p. 862. En la edición de Episodios, de 1915, la contratapa daba aviso de la publicación de ese poemario del cual, en efecto, no he podido localizar más que piezas sueltas. También
Casi todo el resto del año, Rogelio lo dedicó a disertar sobre cuestiones filosóficas y a continuar en la jefatura de Publicaciones del Museo, de donde pasó a dirigir la Biblioteca Nacional de México, ${ }^{48}$ desde noviembre de 1912. No sería desproporcionado afirmar que éste fue uno de sus grandes orgullos como funcionario público pues, como exdirector de la misma, firmó su crónica Episodios.

se informó allí que las obras en preparación se titularían La clave del génesis. Nueva interpretación del texto bíblico basada en las especulaciones de la moderna filosofía y La magia y el espiritismo en las obras de William Shakespeare. Oconitrillo García señala, me parece que equivocadamente, que el libro fue rescatado y publicado por su primo Tomás. En efecto, existe la edición póstuma de poemas: Tomás Soley Güell, "Prólogo”, en Rogelio Fernández Güell, Poesías completas, San José, [s. p. i.], 1918, pp. 7-14, que no incluye algunos poemas que encontré publicados en México, como parte de ese volumen.

48 A su nombramiento, se registraron varios cambios en el personal. La subdirección pasó de Herminio Pérez Alcocer, a José María de Agreda y a Herminio Pérez Abreu en un solo mes. A cargo de la dirección estaba la biblioteca pública "Romero Rubio", en Tacubaya. Desde su gestión, la Biblioteca Nacional abrió la sección de Periódicos y Revistas, tanto los editados en la capital, como los de la República y hasta del extranjero, Boletín de la Biblioteca Nacional, Año X, Nos. 1, 2 y 3, enero-marzo, 1913. Hemeroteca Nacional de México, UNAM. 


\section{Figura 1. Fotografía de portada Episodios de la Revolución Mexicana}

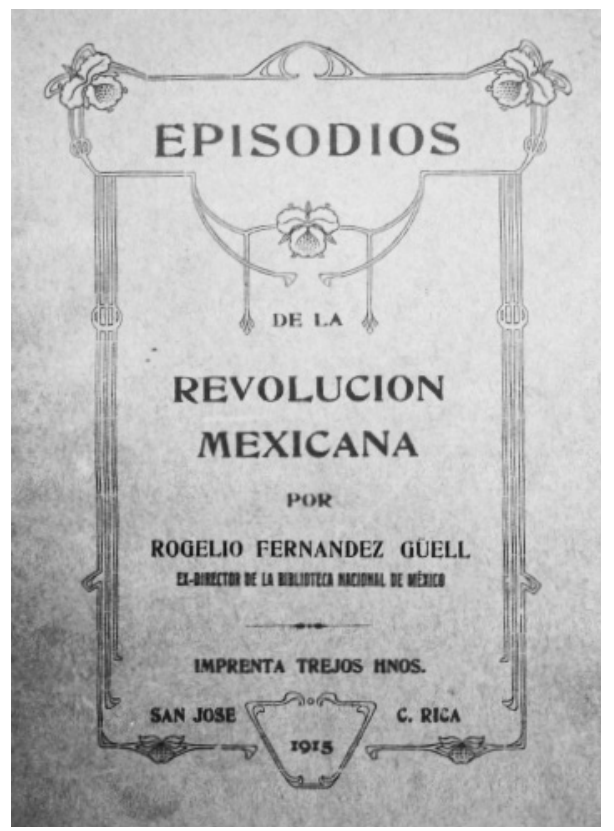

Fuente: Cortesía de la Biblioteca Miguel Obregón Lizano, Costa Rica.

El costarricense no dejaba de hacer proselitismo espírita y, en asamblea, fue nombrado presidente de la Gran Liga Mexicana de Librepensadores. Además, en algún momento, se había hecho masón. En noviembre de 1912, organizó la Fiesta del Librepensamiento, en donde conferenciaba la famosa española Belén de Sárraga. El gobierno, incluso, solventó con una suma los gastos para su realización. ${ }^{49}$

49 El 14 de noviembre de 1912, Juan Sánchez Azcona, secretario particular de Madero, anunciaba al
La crisis política, ya para entonces, estaba apuntando a la caída de Madero. No tengo información sobre cómo Rogelio y su familia sobrellevaron estos últimos meses, hasta el asesinato del Presidente y del Vicepresidente. Sin embargo, Episodios revela que estuvo muy enterado de todos los acontecimientos y que, para una futura redacción de aquel siniestro pasaje de la historia mexicana, ya acopiaba periódicos, noticias, artículos, impresiones y tomaba notas. Quizá el día 16 de febrero de 1913, cuando las dos partes en guerra acordaron una tregua, se atrevió a salir y observar cómo «las calles estaban desiertas, y los contados transeúntes que se advertían, eran vecinos precavidos que aprovechaban los breves instantes de tregua para proveerse de comestibles». ${ }^{50}$

secretario de la Gran Liga, Rafael Pérez Taylor, que, como aportación para la propaganda para el Gran Congreso Nacional, recibirían 5 pesos mensuales, AGN, Fondo Presidentes, Archivo Madero, caja 55, Libro 20, Año 1912, f. 324.

50 Episodios, p. 199. Rogelio señaló que dicha tregua fue el día 9, fecha imposible pues ese día el general Bernardo Reyes murió en el intento de matar a Madero en Palacio Nacional, y de ese modo iniciaría la llamada Decena Trágica. 
A la muerte de Madero y de Pino Suárez, la renuncia de Rogelio a la Biblioteca Nacional de México se apuró. El 1 de marzo se embarcaba para su país natal, trayecto en el que perdió su biblioteca personal y obras de su autoría. ${ }^{51}$ Acababa de cumplir los treinta años.

Su partida implicó el olvido. Casi ninguno de los protagonistas de la revolución citó su obra Episodios, mucho menos aquellas de corte espírita. Lo hallé apenas referido por Bulnes, aquél a quien tanto criticaba: admitía que Rogelio era un "férvido maderista» pero, a la vez, un «hombre de criterio y escritor desapasionado» al dar crédito a su información sobre ciertos pasajes de la crónica, relativos a la Decena Trágica. ${ }^{52}$ Lo leyó también Isidro Fabela al juntar documentos del movimiento armado, que comenzó a publicar, a partir de 1960, bajo el título Documentos históricos de la revolución mexicana. También Federico González Garza lo mencionó en La revolución mexicana. Mi contribución político literaria [Ciudad de México: A. del Bosque, 1936] mientras que Pascual Ortiz Rubio (presidente de México 1930-1932) afirmó haber leído tan «precioso libro» en La revolución de 1910.

51 Tomás Soley Güell, art. cit., p., 13.

52 Véase Francisco Bulnes, Toda la verdad acerca de la revolución mexicana. La responsabilidad criminal del presidente Wilson en el desastre mexicano, Ciudad de México, Los insurgentes, 1960.
Apuntes históricos [Ciudad de México: Ediciones Botas, 1937]. De todos ellos, quizás las referencias más valiosas hayan sido las de otro extranjero, Manuel Márquez Sterling, en Mi gestión diplomática en México, testimonio mejor conocido como Los últimos días del presidente Madero. ${ }^{53}$ Rogelio refirió un manuscrito del cubano, entre finales de 1914 y principios de 1915, pues lo cita. Márquez Sterling publicaría el suyo hasta 1917, en La Habana, y también lo citó. Sin duda, los relatos de ambos se nutrieron mutuamente y no es exagerado afirmar que Episodios está incluso, literariamente hablando, por encima de Los últimos días, de Márquez.

\section{Regresa a la patria}

Casi de inmediato, se incorporó a todas las actividades que realizaba en México pero, ahora, en pro de Costa Rica: "la Patria no saldrá nunca de mí", había sentenciado en aquel lejano enero de 1904, cuando partía a España.

En San José, nada más llegar, dictó la conferencia Máximo Fernández ante la historia y sus contemporáneos, la cual logró ser impresa [San José: Imp. Alsina,

53 Es evidente que Rogelio y Manuel mantuvieron una amistad desde México y que la continuaron cuando ambos regresaron a sus países. Rogelio conoció Mi gestión diplomática en México hacia 1914, poco antes de terminar su libro. Márquez Sterling publicó sus memorias en 1917. 
1913?]. Y, enseguida, puso manos a la obra Episodios. Amén de muchos detalles sobre aquellos años que el historiador podrá encontrar allí, si a ella se acerca (pues no fue publicada en México), ${ }^{54}$ el cronista volvió con digresiones sobre el tema que del cual le era ineludible hablar: la libertad:

Bella es la libertad si se ejercita dentro del orden; divino el pensamiento que vuela a iluminar las conciencias en alas de la hoja periódica; misión sublima la de la prensa, que es el pan de cada día de que habla el Evangelio y que el alma pide al Creador en la oración santa del progreso; mas no hay nada más abominable que la libertad cuando se trueca en licencia y que el pensamiento cuando brilla como un puñal bajo un manto o se desliza como una serpiente entre las flores de un jardín. ${ }^{55}$

Fernández Güell podía constatar cómo el ideal maderista había sido segado con el crimen, producto de una rebelión militar. Y cómo el exceso de libertades, en aquella época, no habían

54 Por primera vez en México saldrá Episodios, preparada por quien esto escribe, a finales de 2017, editada por la Benemérita Universidad Autónoma de Puebla y Miguel Ángel Porrúa.

55 Rogelio Fernández Güell, Episodios, p. 166. rendido los frutos esperados. Esto explicaría sus cambios hacia 1918, cuando detectó que la democracia costarricense estaría en entredicho, como se leerá más adelante. La revolución de nuestro país le había enseñado, conforme escribió, que: "Evidentemente, México aún no estaba apto para la democracia, o deslumbrado por la fácil conquista de las libertades no apreciaba ya la obra de Madero, como el cautivo que, a poco de encontrarse fuera de la prisión, se olvida de la lobreguez de su mazmorra y de las implacables mordeduras del grillete, y le parece que siempre ha gozado del bien presente y desdeña a su libertador". ${ }^{56}$

Se puso al frente de El Republicano y se incorporó al Ateneo de Costa Rica. En 1914, se desempeñó como subsecretario de Gobierno, luego de Fomento y, más tarde, como director general de Correos. ${ }^{57}$ Sus hermanos habían continuado en el periodismo. Y con ellos emprendió, esta vez, El Imparcial, cuyo primer número circulaba en San José desde el 1 de septiembre de 1915. Como puede apreciarse, su compromiso con la política no menguó. También fue electo diputado constituyente por la provincia de San José. Fiel a

56 Rogelio Fernández Güell, Episodios, p. 158.

57 Tomás Federico Arias Castro, "Centenario de la primera obra literaria costarricense sobre la historia de la Revolución Mexicana (1915-2015)", Revista Estudios, No. 31, 2015, p. 13. 
la democracia, en una editorial del 1 de abril de 1917, llamaba a votar porque cada sufragio "condensará el anhelo de los costarricenses de vivir independientes, libres de todo yugo extranjero en el solar de nuestros mayores". 58 Pero su relación con Tinoco pasó de buena a mala. El general mandó clausurar el diario el 25 de julio de 1917, según el testimonio de su madre, Carmen Güell Pérez. ${ }^{59}$

En su país, tanto antes como después de sus periplos por España y México, había escrito, en resumen, cuando menos para El Centinela, El Tiempo, El Día. Diario Independiente, El Derecho (solo duró unos meses, en 1909) ${ }^{60}$, El Republi-

58 Octavio Quesada Vargas, El Imparcial, San José, [s. p. i.], 1921, p. 24. Este librito cuenta el litigio en torno al diario. Él era, a la sazón, el fiscal gubernamental para resolver quién era el dueño legalmente. Ganó la familia de Rogelio, en particular su viuda, Rosa. Un conmovedor detalle: cuando entregaron todo lo incautado, Rosa recibió varias pertenencias de su esposo: una máquina de escribir, plumas y objetos menores; la Biblia del padre Felipe Scío (del siglo XVIII), con anotaciones de su padre, el general Federico Fernández; el diario que éste llevó, relativo a la guerra centroamericana del presidente guatemalteco Justo Rufino Barrios, en 1895 y un retrato grande, enmarcado con hoja de oro, de Francisco I. Madero, pp. 96-97.

59 Octavio Quesada Vargas, op. cit.

60 Desde mayo de 1909, sus hermanos Federico y Víctor habían reemprendido la edición de $E l$ Derecho. Periódico Político, Social y de Intereses Generales. En aquellos momentos, los directivos consideraban que la primera época de El Derecho, ya mencionado, había sido una distinta a la de la segunda. Ahora "no viene como antes á combatir; viene solamente a analizar; no viene como antes cano (en donde empleó los alias Perseo, Viriato y Juvenal ${ }^{61}$ ) y El Imparcial, éste último, por él fundado, como ya se dijo. En paralelo a la escritura de Episodios, al fin pudo sacar La clave del génesis. Filosofía arcana (San José: Imp. El Imparcial, 1915) que tenía preparada desde México. Así también, Verdaguer y su obra [San José: Imp. Alsina, 1915], en el cual abordó a Mosén Jacint Verdaguer, sacerdote catalán y poeta fallecido en 1902 .

Para marzo de 1916, era nombrado secretario del ministro de Relaciones Exteriores de Costa Rica, Julio Acosta García (presidente de 1920 a 1924), y una de sus encomiendas fue representar a la nación centroamericana ante la Alta Comisión Internacional de Legislación Uniforme. Producto de esta misión salió una memoria. ${ }^{62} \mathrm{Al}$ año siguiente, viajó por última vez a España. Pudo publicar allá su polémico libro Plus ultra. La raza hispana

a predicar una República, porque se goza de ella; viene únicamente a participar en una contienda, en lo social y en lo económico pues lo político en la actualidad, está resuelto”. Véase en Federico Fernández Güell, “Otra vez”, en El Derecho. Diario Republicano y de Intereses Generales, San José, Año I, Serie 2, 8 de mayo de 1909, col. 5, p. 2. Sistema Nacional de Bibliotecas de Costa Rica.

61 Eugenio de Triana, "El Ateneo de duelo", Athenea, Año XI, No. 10, San José,1918, pp. 230-231. Sistema Nacional de Bibliotecas de Costa Rica.

62 Rogelio Fernández Güell et al., Alta Comisión Internacional de Legislación Uniforme. Recomendaciones, resoluciones y acuerdos tomados en las sesiones de esta Alta Comisión, verificadas en Buenos Aires del 3 al 12 de abril de 1916, San José, Imprenta Nacional, 1916. 
ante el conflicto europeo (Madrid, Centro Editorial de la Unión Intelectual LatinoAmericana, 1917). La obra la firmaba, en Barcelona, el 31 de enero de 1917. Además de su libro, nació en España su tercer hijo, Luis. El prólogo corrió a cargo de Jacinto Benavente (Premio Nobel de Literatura en 1922) a quien, de toda seguridad, había conocido en España más de una década antes. Este libro le valió ser considerado «germanófilo» en plena Primera Guerra Mundial e, incluso, fue fichado como espía por el gobierno francés, aún meses después de muerto. ${ }^{63}$

Poco antes de morir pudo terminar Lola. Romance de costumbres nacionales [San José: Imp. Alsina, 1918], un poemario que no aparece en su propia relación de obras, de 1918, y que dedicó a la madre de sus hijos, Rosa Serratacó Soley. El prologuista $-\mathrm{X}$. X. X.- le concedió un alto mérito literario pero, sobre todo, "un interés afeccional, por ser el último producto de aquella clara inteligencia, tan violenta como prematuramente extinguida" ${ }^{64}$

Se aproximaba el final de su vida. No deja de llamar la atención que haya escrito un testamento literario, dos meses antes.

63 Journal Officiel de la République Française, Año 50, No. 311, 15 de noviembre de 1918, p. 9902. Bibliotèque National de France.

64 X.X.X., "Al lector", en Rogelio Fernández Güell, Lola. Romance de costumbres nacionales, San José, Imp. Alsina, 1918, p. 3. La conclusión, asentada por el autor, es en San José, en enero de 1918.
Si era asiduo a la consulta con espíritus difuntos, bien puede especularse que fue persuadido de su futura muerte, como su amigo Madero:

He escrito mucho; he proyectado más; y sólo lamento desaparecer antes de haber hecho algo que valiera la pena... ¿Quién sabe? Puede que de vivir cien años tampoco hubiera realizado nada digno de memoria. A lo menos, réstame el consuelo de que ningún Homero ni Lucano fenece, y ese mismo consuelo debe quedarle a las generaciones. Lo siento por los tipógrafos e impresores, a quienes hubiera dado algún trabajo. ${ }^{65}$

Entre otras cosas curiosas, en torno a su prolífica vida literaria, Rogelio asentó que, en México, «quedó inconclusa (por cierto cuando iba a entrar en la parte más interesante)», La magia y el espiritismo en las obras de William Shakespeare, que "se publicó hasta la página 40 en el folletín de Elios [sic]: “¡Lástima!, el Hamlet ofrecía un material abundante e inmejorable para el desarrollo del tema". ${ }^{66}$ Lo publicaba por

65 Rogelio Fernández Güell, "El testamento literario del poeta”, p. 862.

66 Rogelio Fernández Güell, "El testamento literario del poeta", p. 862. Fue un apasionado de la obra de Shakespeare. Varios personajes de sus tragedias los empleó para hacer paralelismos con los personajes de carne y hueso que participaron en la tragedia llamada Decena Trágica, en México. 
entregas en Helios. ${ }^{67}$ Quedó asimismo reducida a intención una novela histórica que titularía Morazán, sobre la vida del capitán salvadoreño, Francisco Morazán, quien se convirtió en Jefe Supremo de Costa Rica a mediados del siglo XIX. Y otra «muy humana y muy divina» que titularía Incesto y en donde "por una curiosa paradoja, lo moral venía a ser precisamente lo inmoral, y viceversa». La relación del autor refirió varios versos, ensayos y reflexiones «desparramados en periódicos y revistas espiritistas». En efecto; hay una gran cantidad de ellos en hemerotecas de Costa Rica, El Salvador, España, México. Pero también esparcidos se hallan sus artículos periodísticos (tanto filosóficos como políticos). He hallado muchos en periódicos costarricenses, españoles y mexicanos. El autor expresó que había deseado agrupar estas colaboraciones en un volumen que se llamaría Chamarasca. ${ }^{68}$

En esta entrega, Fernández Güell continuó explorando la obra del inglés con la ciencia que él estudiaba: «Es absolutamente imposible [...] que Shakespeare hubiera escrito el Hamlet sin conocer las doctrinas de los pitagóricos y neoplatónicos y sin haber llevado a cabo, personalmente, experiencias de mediumnismo". Eduardo Oconitrillo García, op. cit., p. 54.

67 Entre mayo de 1911 y agosto de 1912, en Helios publicó varias disertaciones espíritas, además de la mencionada: "El periespíritu o cuerpo etéreo", "Pluralidad de existencias. Os es necesario nacer otra vez, Jesús», «Materialización de los espíritus”, "El demonio de Sócrates" y "Pensativo en la noche”, en, Martha Celis de la Cruz, art. cit., p. 168.

68 Rogelio Fernández Güell, "El testamento literario del poeta”, p. 862 .
En toda su obra, sobresalió su devoción por autores espíritas como Allan Kardec o Camille Flammarion (y dedicó un poema a la escritora Amalia Domingo Soler cuando falleció, en 1909). Los principios propagados por Buda, como aquel de «las vidas sucesivas» sentaron las bases del espiritismo moderno, según Fernández Güell: «se le condena por su interpretación del Nirvana, creyéndose que él buscaba la libertad del alma en su extinción completa». ${ }^{69}$

Los clásicos grecolatinos fueron un referente como para todo autor de su época; en particular, de Cimón, ${ }^{70}$ Sócrates, Juvenal, Tácito, Demóstenes, Lucano, Homero, Sófocles y Esquilo, además de las historias clásicas de tiranos en las personas de Lucio Quincio Cincinato, Pisístrato, Tiberio, Calígula y Nerón. También las historias de los césares y de reyes como Enrique IV, del Sacro Imperio Germánico; los Católicos de España, incluido Carlos V o Luis XVI, aún, Oliverio Cromwell. Sobresale su cultura en torno a los hechos y pensamiento político de la revolución francesa, del siglo XVIII, con oradores o militares como Pierre Victurnien Vergniaud o el marqués de La Fayette; o los héroes Dantón y Jean Marie Barbaroux. Entre

69 Rogelio Fernández Güell, Psiquis sin velo, p. 37.

70 Fue un estadista y militar ateniense de donde, como se puede observar, tomó el pseudónimo empleado en el bisemanario La Época. 
los poetas del Romanticismo, evocados en sus obras, apareció Lord Byron, el cubano José María Heredia, Manuel Silvela y García de Aragón, Víctor Hugo, Eugenio Sue; pintores como Francisco de Goya y pensadores como Giordano Bruno y hasta Proudhón. Por supuesto, conocía bastante de la historia de México, desde la precolombina, hasta la última Guerra de Reforma que había vivido el país. Entre sus admirados estuvo también León Tolstoi, muerto en 1910. Por supuesto, William Shakespeare y Miguel de Cervantes, referentes que recorren, en general, sus reflexiones y creaciones. Sin embargo, considero, el principalísimo fue Jesús de Nazaret. Rogelio fue un cristiano universal.

\section{Apuntes varios sobre su asesinato}

Bastante más podrán aportar nuevas generaciones de historiadores mexicanos y costarricenses en torno a los últimos años de vida de Rogelio Fernández Güell. Él llegó de vuelta a Costa Rica luego de un periplo de nueve años: estaba casado, tenía dos hijos y tres libros publicados; además, ya era un famoso conferencista espírita, había dirigido dos diarios, colaborado en un tercero, y, en el gobierno maderista, había tenido el honor de dirigir la cultura del país, desde la Biblioteca Nacional de México. Después de publicar Dos revolucionarios a la sombra de Madero. La historia de So- lón Argüello Escobar y Rogelio Fernández Güell (Ciudad de México, Ariel, 2016) encontré un ejemplar autografiado por Marcelino García Flamenco, de Repertorio Americano, en 1926. ${ }^{71}$ Amén de las erratas que, según señala, hubo en su primera declaración, Marcelino fue, en verdad, el testigo valiente que pudo revelar que la orden de su asesinato había provenido de altas esferas del gobierno costarricense. Después de presenciar los hechos, el 15 de marzo de 1918, "en mi calidad de hombre honrado, en enemigo franco del gobierno de los señores $\mathrm{Ti}$ nocos”, escribía, se declaraba dispuesto a denunciar el asesinato de Rogelio y de sus acompañantes, ocurrido en Osa. Se trataba del grupo guerrillero al que pertenecían Joaquín Porras, Carlos Sancho, Jeremías Garbanzo y Ricardo Rivera. ${ }^{72}$ La declaración era dada a conocer en Panamá porque, en Costa Rica, «no hay quien me la reciba». Marcelino pudo ver los cadáveres de los caídos. Se impresionó al observar el del poeta y periodista:

71 Un ejemplar del diario fue firmado por el propio autor en una notita, a mano, dirigida a Jorge Volio "con la colección de erratas que no tuve oportunidad de hacer antes de la impresión de este folleto. Panamá, 20 de abril de 1918. M. García Flamenco". Marcelino García Flamenco, "Para la historia de Costa Rica. El asesinato político del exdirector de El Imparcial y diputado al Congreso, don Rogelio Fernández Güe11", Repertorio Americano, Tomo XIII, No. 4, San José Costa Rica, 31 de julio de 1926, p. y ss. Biblioteca electrónica Scriptorium de la Universidad Nacional de Costa Rica.

72 García Flamenco, Marcelino, Para la historia de Costa Rica, Panamá, Imprenta Star and Herald, 1918. 
[...] medio oculto en el monte, encontré el cadáver de don Rogelio, que presentaba una herida lateral en la rodilla izquierda, dos agujeros de bala en el cuello y dos en el cárneo, la barba y el bigote rasurados y vestido con ropa exterior sencilla, una camisa con pechera a rayas delgadas de azul y blanco, cotas de ciudad a dos colores e indumentaria interior toda fina y marcada delicadamente con las dos primeras iniciales de su nombre. ${ }^{73}$

Para entonces, la mirada del profesor salvadoreño había advertido que el cadáver "ya había sido despojado de todo lo valioso". El comando asesino era tripulado por Patrocinio Araya,${ }^{74}$ quien hizo el tiro de gracia. Porque Marcelino escuchó "decir que Araya había ultimado, sin necesidad a Fernández Güell”. A él preguntó sobre éste último tiro y el policía, jactancioso, confirmó: "Sí, yo lo maté con mi propio puño [...], con mi revólver, yo no llevo máuser". Y segundos después: "A esa gente no podía llevarla viva, maestro, tenía órdenes expresas". ${ }^{75}$

73 Marcelino García Flamenco, art. cit., p. 51.

74 En una carta al ministro de Guerra, Araya confirmó haber cumplido sus órdenes por la mañana de ese 15 de marzo. "Puede decir al amigo Enrique Claire q[ue] cuente con el crespo q[ue] me encargó de Rogelio", Eduardo Oconitrillo García, op. cit., p. 13.

75 Marcelino García Flamenco, art. cit., p. 51.
Así terminaba la vida revolucionaria para Rogelio Fernández Güell. El 22 de febrero, justo al cumplirse un lustro del asesinato de su amigo Francisco I. Madero, él se alzaba en armas contra su otrora amigo, el presidente Federico Tinoco Granados. La revista Athenea, de Costa Rica, a mirar lo que son las cosas, dio cuenta del fallecimiento a través de un adversario político del pasado: Eugenio de Triana. Le reconocía sus talentos y brindaba por el honor, escribió, de "quien tenía el poder supremo de la pluma y el vigor imponderable de un espíritu fuerte". ${ }^{76}$ Tres días después de morir asesinado llegaba la notificación de que había sido nombrado académico por la Real Academia Hispanoamericana de Ciencias y Artes de Cádiz. En mayo de 1918, dicha publicación sacó Cuando yo muera, del poeta abatido:

Cuando pague tributo a la Natura y mi espíritu vuelva a su morada si tú existes aún, mi dulce amada, dáme al pie de algún árbol sepultura.

En marmóreo sepulcro no me entierres

que es lujo y necedad la humana pompa;

no podrás impedir que me corrompa,

76 Eugenio de Triana, "El Ateneo de duelo", Athenea, San José, Año XI, No. 10, 1918, p. 230. 
aunque en caja de sándalo me entierres.

Entiérrame a la orilla de una fuente

y cultiva un jardín sobre mi fosa, y así, mi corazón trocado en rosa, llenará de perfumes el ambiente. Mas prefiero ser fruto sazonado que flor para los ángeles nacida; en vez de grata esencia ser comida,

y ofrendarme hecho pan al desgraciado.

Dáme al pie de algún sepultura do pudriéndome, al bortde de un camino,

calme el hambre y la sed del peregrino y le brinde frescor con mi verdura $^{77}$.

Un posterior homenaje vino de sus antiguos colaboradores espíritas de Barcelona:

El culto escritor y admirable poeta era un hombre de ancha conciencia, de bondad suprema y liberal en alto grado que cayó en desgracia precisamente por ejercer el sacerdocio del espíritu y por ser amante entusiasta de la libertad, de la justicia y de la ra-

77 Rogelio Fernández Güell, "Cuando yo muera», Athenea. Órgano del Ateneo de Costa Rica, Año XI, No. 11, 1 de mayo de 1918, p. 1. zón. Liberal probado, luchó toda su vida por los ideales de un cristianismo sin reserva; su palabra y sus escritos predicaban constantemente la doctrina de una moral sana, justa y beneficiosa para todos, pero los ignorantes y los perversos levantaron barricadas de odio ante su persona, y perseguido se decidió a abandonar a su país [...]. No pudo conseguir su anhelada idea, y unos miserables le enviaron unas balas que dieron con su cuerpo en tierra, elevándose su espíritu a donde las miserias humanas no pueden llegar y en donde todo es luz, amor y perdón, que enviaron sus verdugos. ${ }^{78}$

En todo México, no hay una sola calle, parque, escondido busto o placa conmemorativa de su paso por la República. Sus libros, y no todos, son difíciles de conseguir; acaso en la Biblioteca Nacional se encuentra Psiquis sin velo y Lux et umbra, y en la Universidad Panamericana, en la capital, un ejemplar incompleto (llega a la página 172) de Episodios de la revolución mexicana. Justo sea, aunque sea de modo tan tardío, honrar la memoria de este congruente liberal, filósofo y escritor, y sacar de ese

78 Luz, unión y verdad, Barcelona, Año XIX, No. 6, junio de 1918, p. 103. 
imperdonable olvido a quien alcanzó la cima intelectual y poética en el mundo hispano; a un personaje de ideales tan altos, un visionario, un demócrata a carta cabal y que luchó, aún fuera de su país natal, al lado del primer y único presidente democrático de México, en el siglo XX, Francisco I. Madero. 